\title{
Is the existence of species paid more importance in the nature's processes of evolution than the survival of an organism while causing maintenance of diversity of the species.
}

\author{
Varun saxena
}

\begin{abstract}
In nature, during evolution many senses and systems have developed in the organisms for their survival. It is known that evolution uses the process of mutation for creating better chances of survival of the species according to their surroundings. Generally an organism protects itselffor its own survival but there are some facts presented in this paper which support the theory that in nature, the existence of species is given more priority over survival of an organism and has affected evolution of various organisms.
\end{abstract}

\section{Introduction}

It is seen that without any prior experience the organisms of many species are able to respond according to their needs of survival because of their innate hardwired memory. This innate hardwired memory and some other characteristics of the organisms have got driven in the nature's process of evolution in such a way that the existence of species is paid more importance than survival of organism.

\section{Reproduction}

It is a process by which an organism replicates itself. Reproduction does not help in the survival of the organism but it is important for the existence of a particular species. Various multi-cellular organisms and unicellular organisms reproduce for the better chances of existence of their species.

\subsection{SIZE OF ORGANISM}

It is seen that some organisms are large and some are small according to their average size while some organisms have longer average lifespan and some have smaller average lifespan. It is also seen that some organisms have higher reproduction rates and some have lower rate of reproduction. In this paper, it is shown that the organisms which reproduced fast became small or their average lifespan decreased and organisms which reproduced slowly became large in their average size or their average lifespan increased.

\subsection{COMPARISON OF REPRODUCTION RATES, SIZES AND AVERAGE LIFESPANS OF UNICELLULAR ORGANISMS}

The average size of bacteria is around half to five micrometers in length, the average size of a fungus cell is around five to 50 micrometers and the average size of a virus is around 10 to $300 \mathrm{~nm}$.

It can be seen that the average lifespan of fungi is more than the average lifespan of bacteria. And also the average lifespan of bacteria is more than average lifespan of virus.

It is known that a virus reproduces faster than bacteria and bacteria reproduce faster than fungi.

\subsection{COMPARISON OF REPRODUCTION RATES, SIZES AND LIFESPANS OF MULTI-CELLULAR ORGANISMS}

\begin{tabular}{|l|l|}
\hline Species & Average Lifespan \\
\hline Dog & $22 \mathrm{yrs}$ \\
\hline Cat & $25 \mathrm{yrs}$ \\
\hline Bear & $40 \mathrm{yrs}$ \\
\hline Donkey & $45 \mathrm{yrs}$ \\
\hline Camel & $50 \mathrm{yrs}$ \\
\hline Bull & $28 \mathrm{yrs}$ \\
\hline Mouse & $1 \mathrm{yr}$ \\
\hline Horse & $40 \mathrm{yrs}$ \\
\hline Lion & $35 \mathrm{yrs}$ \\
\hline Housefly & $20 \mathrm{days}$ \\
\hline Mosquito & 3 days \\
\hline American Alligator & $56 \mathrm{yrs}$ \\
\hline Bull & $28 \mathrm{yrs}$ \\
\hline Crocodile & $45 \mathrm{yrs}$ \\
\hline Hippopotamus & $45 \mathrm{yrs}$ \\
\hline
\end{tabular}




\begin{tabular}{|c|c|}
\hline Koala & 8 yrs \\
\hline Tiger Salamander & $11 \mathrm{yrs}$ \\
\hline Tree Frog & 14 yrs \\
\hline Wood Duck & $22.5 \mathrm{yrs}$ \\
\hline Wolf & $18 \mathrm{yrs}$ \\
\hline American Toad & $15 \mathrm{yrs}$ \\
\hline Bat & 24 yrs \\
\hline Beaver & $20 \mathrm{yrs}$ \\
\hline Canada Goose & $24.3 \mathrm{yrs}$ \\
\hline Chicken & $14 \mathrm{yrs}$ \\
\hline Common Goldeneye & $14.3 \mathrm{yrs}$ \\
\hline Cow & $22 \mathrm{yrs}$ \\
\hline Deer & $26.8 \mathrm{yrs}$ \\
\hline Elephant & $70 \mathrm{yrs}$ \\
\hline Domestic Pigeon & $18 \mathrm{yrs}$ \\
\hline Fox & $14 \mathrm{yrs}$ \\
\hline Goat & $15 \mathrm{yrs}$ \\
\hline Guinea Pig & 8 yrs \\
\hline Kangaroo & $9 \mathrm{yrs}$ \\
\hline Galapagos Land Tortoise & 193 yrs \\
\hline Grey Squirrel & $20 \mathrm{yrs}$ \\
\hline Macaw & 64 yrs \\
\hline Mongoose & $12 \mathrm{yrs}$ \\
\hline Mynah & $25 \mathrm{yrs}$ \\
\hline $\mathrm{Ox}$ & $20 \mathrm{yrs}$ \\
\hline Pig - wild & $25 \mathrm{yrs}$ \\
\hline Platypus & $10 \mathrm{yrs}$ \\
\hline Rabbit & 9 yrs \\
\hline Rhinoceros & $40 \mathrm{yrs}$ \\
\hline Sheep & $15 \mathrm{yrs}$ \\
\hline Tiger & 22 yrs \\
\hline Trumpeter Swan & 33 yrs \\
\hline Woodchuck & $15 \mathrm{yrs}$ \\
\hline Wombat & $15 \mathrm{yrs}$ \\
\hline Superb Parrot & $36 \mathrm{yrs}$ \\
\hline Toucan & $20 \mathrm{yrs}$ \\
\hline
\end{tabular}

Fig. 1 Species and their corresponding average life-spans.

To judge the connections precisely, small sized species are compared. According to the Fig. 1, the average lifespan of a housefly is 20 days, the average lifespan of a mosquito is three days and the average life span of a mouse is about 12 months.

It is known that the average size of mouse is greater than average size of housefly and average size of housefly is greater than mosquito.

\section{Conclusion}

The average sizes and life-spans of some species is more than some other species. It can be seen that the average size and average lifespan is varying in the species having similar body structures and ways of reproduction.

Looking at the facts, it can be seen how the rate of reproduction is related to the average size and average lifespan of the species. The reproduction rate seems to have influenced genes of age and size in the organisms and gives an indication that the existence of a particular species has been paid more importance than the average lifespan and size of the species during the evolution.

If reproduction rates had been higher in large sized and long aged species, it would have resulted in a massive population and utilization of the resources of earth, causing a lot of breakdowns in the food web. As a solution to this problem, the balance in the variety of the species has got maintained in nature through a balance in the average reproduction rate, average size and average lifespan of the organism.

This creation and maintenance of balance in the reproduction rate, average size and average lifespan of the species gives an indication that the existence of a particular species with a controlled population has been paid more importance than the survival of an organism of particular specie resulting in maintenance and presence of a large variety of species on earth.

\section{Eyes And Blood Color Relation}

When multi-cellular mobile organisms were evolving in water during primitive period of life, the organisms belonging to a species would have been lesser in number and living at some distance apart from each other. The organisms of particular species were attacked by another advanced or specifically designed predator species for food and other demands for survival. During this period, when the eyes were not evolved in the 
species, a method of sending danger signal to same type of species got developed using the properties of waves. The red wavelength wave is least dispersive and therefore best amongst the various abundant waves reaching on the earth's surface just after the infra-red wave for following the long distances precisely. The infrared waves were sensed as heat by the various organisms, so they were not utilized for this purpose.

It seems that the multi cellular organisms which were generally living in water or above the land got evolved with red colored blood in order to send the danger signal farther and accurately for properly locating the mobile organisms rather than scattered one, like green in immobile plants.

Some organisms which generally lived inside the soil have white or yellow colored blood. E.g. cockroaches and ants. These colors of blood seem to have evolved in these organisms due to the darkness present inside the soil. Only highly reflective pigments could send the danger sign through waves. These organisms i.e. cockroaches and ants have eyes which cannot see proper red, maybe because it is not so important for them to survive as a species. This indicates a natural intra-species interconnection for preservation of species.

\section{Suicidal Fights}

Some organisms like lion have been seen dying for the protection of their progenies. This seems to be an innate memory behavior in which parents try to protect their child even at the cost of their own life. This also forms evidence indicating that the existence of species got more importance than the survival of an organism itself during evolution.

\section{Conclusion}

It seems like although many mutations have occurred for the survival of organisms but the existence of species has been paid more importance in the coding of genes than the survival and long life of an organism. And all these processes are prevalent in such a way that the balance of resources on earth and food web are not disturbed.

[1]. sonic.net/ petdoc/lifespan.htm

\section{References}

[2]. www.wikipedia.com 